\title{
Formats for other-initiation of repair across languages
}

\author{
An exercise in pragmatic typology
}

\author{
Mark Dingemanse ${ }^{1}$, Joe Blythe ${ }^{1,2}$ and Tyko Dirksmeyer ${ }^{1}$ \\ ${ }^{1}$ Language \& Cognition Department, Max Planck Institute for \\ Psycholinguistics / ${ }^{2}$ School of Languages and Linguistics, University of \\ Melbourne
}

\begin{abstract}
In conversation, people regularly deal with problems of speaking, hearing, and understanding. We report on a cross-linguistic investigation of the conversational structure of other-initiated repair (also known as collaborative repair, feedback, requests for clarification, or grounding sequences). We take stock of formats for initiating repair across languages (comparable to English huh?, who? $y^{\prime}$ mean $X$ ?, etc.) and find that different languages make available a wide but remarkably similar range of linguistic resources for this function. We exploit the patterned variation as evidence for several underlying concerns addressed by repair initiation: characterising trouble, managing responsibility, and handling knowledge. The concerns do not always point in the same direction and thus provide participants in interaction with alternative principles for selecting one format over possible others. By comparing conversational structures across languages, this paper contributes to pragmatic typology: the typology of systems of language use and the principles that shape them.
\end{abstract}

Keywords: typology, conversation, repair, pragmatics, pragmatic typology

\section{Other-initiation of repair}

How do speakers of different languages deal with problems of speaking, hearing, and understanding? This paper is a typological study of formats for other-initiated repair in conversation. We show that, across languages, the inventories of formats for other-initiated repair make use of a recurring set of linguistic resources. The remarkable cross-linguistic similarities point to a common set of underlying factors that shape these formats and guide their selection in interaction. 
A typical other-initiated repair sequence consists of a three-turn structure produced by two speakers, exemplified in Extract 1. At line 1 speaker A produces a turn at talk that A's recipient B treats as problematic by initiating repair (at line 2 ) on the prior turn. The trouble is then repaired by A at line 3, followed by B's uptake at line 4:

Extract 1. Sibbie's sister (Schegloff, Jefferson \& Sacks 1977:367)

1 A Oh Sibbie's sistuh hadda ba:by bo:way. T-1

2 B who? TO

3 A Sibbie's sister. $\quad T+1$

4 B Oh really?

Instances of other-initiated repair (henceforth OIR) can be structurally diagrammed as a sequence of three turns $\mathrm{T}-1, \mathrm{~T} 0, \mathrm{~T}+1$ (Enfield et al. 2013). The linchpin of the OIR structure is the repair-initiating turn by $\mathrm{B}$, which signals a problem in the previous turn and projects a solution in the next. As the temporal mid-point of the sequence, we label its position T0. It looks back towards T-1, the turn that is or contains the trouble-source. The prospective repair-solution occurs at position $\mathrm{T}+1$. The participants in the sequence are $\mathrm{A}$ (speaker of $\mathrm{T}-1$ and prospective provider of $\mathrm{T}+1$ ) and $\mathrm{B}$ (the person initiating repair). This three-part sequence is the prototypical structure for other-initiated repair. In it, the elements of repair (self and other, trouble source, repair initiation, and repair solution) can be observed separately, providing a cross-sectional view of the machinery for repair in interaction. No natural language investigated so far has been found to lack this kind of OIR sequence (Enfield et al. 2013; Schegloff 1987). As a commonly occurring sequential structure with similar form and function across languages, other-initiated repair provides a perfect locus for cross-linguistic examination. In this study, we focus mainly on the centrepiece of the sequence: T0, the turn in which repair is initiated. ${ }^{1}$

Although in theory it would be possible for a language to feature just one format for initiating repair (e.g. huh?), we find that natural languages make available inventories or systems of formats. In their study of repair in American English conversation, Schegloff, Jefferson \& Sacks (1977, henceforth SJS) found the following five types of formats for the other-initiation of repair:

- Huh? and What?;

- the question words Who?, Where?, When?;

- partial repeats of the trouble-source turn plus a question word;

- partial repeats of the trouble-source turn;

- Y'mean plus a candidate understanding of the prior turn. 
One of the aims of SJS was to show the generic nature of repair as "the selfrighting mechanism for the organization of language use in social interaction" (1977:381). Indeed an important aspect of repair is its context-free nature: the fact that anything in talk can be a source of trouble and thereby is potentially a "repairable" (1977:363). But although repair as an organisation may be generic, the way it is implemented is always tied to particular linguistic systems. After all, formats like the wh-question words who, where, when, and the preface $y^{\prime}$ mean are specific formats for other-initiated repair in (American) English, built from the morphosyntactic resources of the (American) English language (for more detailed investigations of the English OIR system, see Benjamin 2013; Purver 2004). Is the other-initiation of repair carried out in similar ways across different languages? What are the types of linguistic resources recruited for the other-initiation of repair, and why are those resources recruited and not others? How do the formats within a language relate to each other, and what interactional work do speakers do in selecting one format over others? These are the questions we pursue in this paper. They are questions of what we call pragmatic typology: the typology of systems of language use and the principles that shape them.

Other-initiated repair, as a sequential structure jointly produced by two speakers, is a phenomenon that can only be studied in interaction. In this paper we use data from cross-linguistic corpora of informal conversation collected in 11 field sites across the globe (Table 1; and see Enfield et al. 2013; Dingemanse \& Floyd in press). We locate sequences of other-initiated repair in these conversational corpora, and within these sequences, we study the formats with which repair is initiated. We find that formats for other-initiated repair display remarkable similarities across languages, and we propose functional principles that explain these similarities.

Table 1. Languages investigated in this study with the contributing researchers

\begin{tabular}{llll}
\hline Language & Classification & Fieldsite & Researcher \\
\hline Cha'palaa & Barbacoan & Ecuador & Simeon Floyd \\
Chintang & Kiranti & Nepal & Tyko Dirksmeyer \\
Dutch & Germanic & The Netherlands & Mark Dingemanse \\
English & Germanic & United Kingdom & Kobin Kendrick \\
Icelandic & Germanic & Iceland & Rósa Gísladóttir \\
Italian & Romance & Italy & Giovanni Rossi \\
Lao & Tai & Laos & N.J. Enfield \\
Mandarin & Sinitic & Taiwan & Kobin Kendrick \\
Murrinh-Patha & Southern Daly & Australia & Joe Blythe \\
Russian & Slavic & Russia & Julija Baranova \\
Siwu & Kwa & Ghana & Mark Dingemanse \\
\hline
\end{tabular}




\section{Mutual understanding in conversation}

Repair in conversation deals with the task of establishing and maintaining mutual understanding. Before investigating the formats used for repair initiation across languages, it is useful to review what is involved in arriving at mutual understanding.

Understanding is not a state that automatically comes about when information is imparted from one speaker to another. It is co-constructed by participants in conversation and requires joint work (Clark \& Schaefer 1987; Clark 1996; Schegloff 2006). Early studies of conversational repair recognised this by characterising repair as an organisation dealing with "problems in speaking, hearing and understanding" (SJS), showing that the troubles targeted by repair can be distributed across participants (self, other) and can be located at different levels (speaking, hearing, understanding). Although the terms speaking, hearing and understanding have sometimes been interpreted as three subcategories of other-initiated repair (Svennevig 2008), they conflate some important distinctions. Disfluencies and matters of word selection are different types of interactional problems, underspecified by a term like "problems of speaking". Likewise, the problem of recognising a word as a name, and that of knowing who this name refers to, are two distinct "problems of understanding".

The process of reaching mutual understanding can be decomposed into several levels (Selting 1987a; Clark \& Schaefer 1987). A useful general characterisation of levels of understanding is provided by Clark's (1996:152) concept of an "action ladder". Clark, building on Austin's (1962) distinctions of levels of speech acts, notes that successful communication is grounded in joint actions by speaker and addressee at the following levels:

Table 2. The Austin/Clark action ladder

\begin{tabular}{lll}
\hline Level & Speaker A's actions & Addressee B's actions \\
\hline 4. & A is proposing joint project $w$ to B & B is considering A's proposal of $w$ \\
3. & A is signalling that $p$ for B & B is recognizing that $p$ from A \\
2. & A is presenting signal $s$ to B & B is identifying signal $s$ from A \\
1. & A is executing behaviour $t$ for B & B is attending to behaviour $t$ from A \\
\hline
\end{tabular}

In the Austin/Clark action ladder, higher levels depend on lower levels in terms of causality (higher levels are implemented by means of lower ones) and entailment (completion of a higher level entails completion of the ones below it). As a corollary, the action ladder exhibits the property of "downward evidence": evidence that $B$ recognized A's intended action (level 4) is also evidence that B succeeded in interpreting A's words (level 3), that B correctly identified the words (level 2), and 
that B attended to A's vocalisation (level 1). All four levels are involved in building mutual understanding, and each of them can be a locus of trouble. ${ }^{2}$

This characterisation of the problem space makes visible some constraints on the selection of formats for repair initiation. For instance, the availability of repair initiation formats depends on the level of the action ladder that was reached. Repetition is a commonly used device in the other-initiation of repair, but if something was imperfectly produced by A or not attended to by B (level 1), repetitionbased formats will not be available. Conversely, the format selected by B can be inspected by A for its downward evidence. An interjection like huh? entails at least that some expressive behaviour was perceived (level 1), but not much more than that, and therefore indicates that there was likely a low-level problem. A question word like who? entails not only that some words were perceived, but also that they were identified by $\mathrm{B}$ as a person reference, and therefore indicates that the problem likely lies at the level of signalling and recognition.

The Austin/Clark action ladder describes the problem space, but it does not determine the selection of formats for repair initiation. If B attended to A's utterance, identified the words, and succeeded in interpreting them, a wide range of formats - from huh? to candidate understandings - will be available for initiating repair. Choosing one over the other has interactional implications: for instance, saying huh? puts the onus on A to figure out the trouble and solve it, whereas providing a candidate understanding puts forward a hypothesis that $\mathrm{A}$ only needs to confirm or disconfirm. The selection of formats can be exploited to do interactional work. In that sense the action ladder represents not only a problem space but also a possibility space.

Locating and characterising the trouble forms only one dimension of the interactional issues presented by other-initiated repair. Two further aspects are important. First, when interactional trouble is made overt (rather than passed by, as happens often enough), this brings up questions of responsibility for the trouble as well as its resolution. We will see that different formats offer different ways of dealing with the question of responsibility. Second, sequences of other-initiated repair also reveal interlocutors to have different levels of knowledge. The clearest indication of this is that in every language, most repair initiators are formatted as questions (presenting B as knowing less than A). More subtly, different formats for repair initiation allow for different ways of tilting the epistemic gradient. The three aspects of trouble, knowledge, and responsibility will return throughout our discussion of different formats for other-initiation of repair.

Following previous work on repair (Schegloff 1997; Fox, Hayashi \& Jasperson 1996), we distinguish between practices and devices. Practices are generic, language-agnostic techniques like 'repetition' and 'questioning.' Devices are particular, language-specific linguistic resources like 'particles', 'question intonation 
melodies', or 'noun-class specific interrogatives'. Following Sidnell (2006; 2010a) we use the notion of formats. Formats combine generic practices and languagespecific devices to deliver social actions.

\section{Open formats}

Across languages, a basic distinction can be made between two types of formats based on the scope of their focus. Some formats do little more than signal that there is a problem with the previous turn. These have been termed "open' class initiators" (Drew 1997) essentially because the question as to where exactly the trouble lies remains open. Such initiators rely on adjacency to broadly focus on the problematic prior turn (Jefferson 1972). These open repair initiators contrast with restricted repair initiators (called "closed' class" by Drew), which restrict the problem space by more precisely locating or characterising the trouble within $\mathrm{T}-1$.

\subsection{Interjections}

One of the simplest and most widespread techniques for initiating repair is to use an interjection like English huh?. Extract 2 presents an example from MurrinhPatha, a language of Northern Australia. Two women, Carol and Agnes, are reminding Maggie (who is quite hard of hearing) that she once saved the life of Agnes' father when he was bitten by a snake. ${ }^{3}$

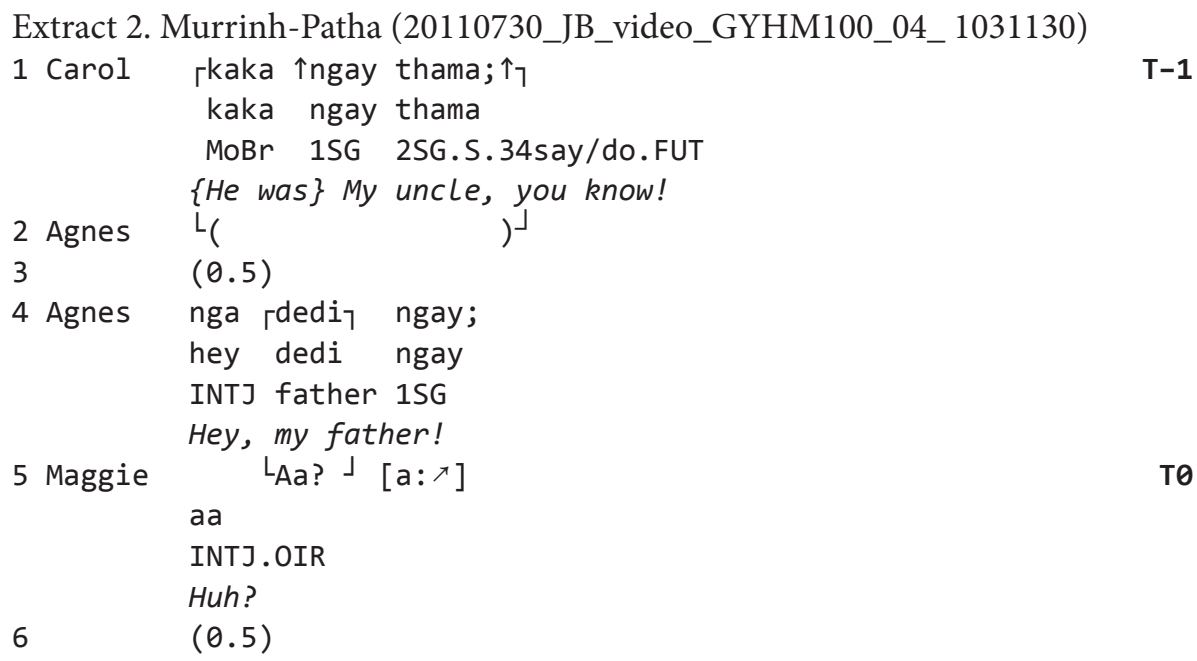


7 Carol kaka ngay thama.

kaka ngay thama

MoBr 1SG 2SG.S.34say/do.FUT

\{He was\} My uncle, you know!

8

$(1.1)$

In an overlapped utterance, Carol (at line 1) points out that the man was her uncle. Also in overlap, Maggie (at line 5) uses the interjection Aa? to initiate repair. At line 7 Carol produces a verbatim repeat of the overlapped utterance (albeit at a lower pitch-register) kaka ngay thama, 'my uncle, you know' She thus treats the problem as an audibility issue.

Interjections for repair initiation are not only widespread, they are also remarkably similar in phonetic form across languages (Dingemanse, Torreira \& Enfield 2013). Invariably they consist of a codaless monosyllable with a vowel from the low-front region of the possible vowel space, with onsets (if present) restricted to glottal constriction $(/ \mathrm{h} /, / \mathrm{P} /)$. Their intonation may tap into the crosslinguistically common link between high or rising pitch and appeal or uncertainty (Gussenhoven 2004; Ohala 1984), but it also appears to be calibrated to the interrogative prosodic system of the language, as we find interjections with falling intonation in languages like Icelandic and Cha'palaa, where this is one of the preferred intonation contours for questions (Dehé 2009:27; Simeon Floyd, p.c.). Table 3 illustrates this.

Table 3. Interjections for initiating repair in seven languages ${ }^{4}$

\begin{tabular}{ll}
\hline Language & Format \\
\hline Cha’palaa & a: $\searrow$ \\
Chintang & hã $\nearrow$ \\
Dutch & hз $\nearrow$ \\
Icelandic & ha $\searrow$ \\
Murrinh-Patha & a: ${ }^{\nearrow}$ \\
Siwu & ã: ${ }^{\nearrow}$ \\
Tai/Lue & hă $\nearrow$ (Moerman 1977:874) \\
\hline
\end{tabular}

What is it about an interjection like huh that makes it useful for initiating repair? With the Austin/Clark action ladder in mind, it is easy to see that a generic open form fulfils a crucial need. Trouble may originate at any rung of the ladder, including the lowest one (execution/attention). There is thus a need for a format that does nothing more than signalling that there is a problem with a previous utterance. This is exactly what the interjection does, and what it does well. However, these considerations do not explain the form of the interjection - the same work could be done with bibibi. The strong similarities of huh? across languages are 
probably best explained by its interactional environment, which is the same in all languages (Dingemanse, Torreira \& Enfield 2013). Turn-taking pressures favour a short form that can be quickly produced to signal trouble. A concise interjection with all articulators in neutral position is well-placed to do this. To fulfil its job as an all-purpose repair initiator, this minimal interjection carries an intonation contour that has been previously characterised as "appeal" (Du Bois et al. 1993) or "questioning" (Jefferson 1972), effecting a volley-like return of the floor to the preceding speaker.

As a contentless question, the OIR interjection interrogates the prior turn for its shortcomings, placing the entire onus on the trouble-source producer to divine the source of the trouble. This is quite an imposition to make on one's interlocutor. Perhaps that is one of the reasons for the existence of other types of open repair initiators, among them single question words and apology-based forms.

\subsection{Question words}

The practice of using single question words like what? for open repair initiation is widespread across languages (Enfield et al. 2013). ${ }^{5}$ Extract 3 below presents an example from English, where what? solicits a repeat of almost the entire prior turn (A:nd and okay being treated as "dispensables" (Schegloff 2004: 100)).

Extract 3. English: open what? (Schegloff 1997:515)

1 Bonnie A:nd (3.0) okay d'you think you c'd come? pretty much for sure?

2 Marina What?

3 Bonnie D'you think yuh c'd come pretty much for sure? T+1 4 Marina Sure.

Whereas an interjection like huh? appears to be fairly specialised for its role in repair (and its other known uses appear to be derivable from this role), a question word like what is an item that is recruited from a larger system of interrogative resources. This raises two questions. First, why is this question word recruited as opposed to other available ones? Second, how do speakers signal this function of what as opposed to its other possible functions?

It is useful to start with the second question. Clearly the lexical items corresponding to 'what' are not only used for open repair initiation. Schegloff (for American English, presumably) reports two distinct what formats: one with fully rising intonation and the other with falling or continuing intonation (1997:516). He argues that only what? with rising contour, as in line 3 of Extract 3, targets the entire preceding turn. By contrast, what. with a falling contour, as in Extract 4 below, targets the referentially vague expression some in line 1 . In response, a 
specification of the referent ('saline solution') is provided at line 5. In other words, the downward intoned what functions as a restricted repair initiator.

Extract 4. English: restricted what. (Schegloff 1997:515)

1 Shane Lemme have some (0.2) Lemme hev- cz I ran ou :t. T-1

$2 \quad(0.4)$

3 Michael What .

$4 \quad($.

5 Shane u-Saline solution gunnah gîts s'm duhmorr' T+1

$6 \quad(0.7)$

7 Michael Mm: .

Thus in English there are two separate repair formats utilizing the same lexical item, each with distinct intonational contours, deployed for distinct repair practices. Similar distinctions have been reported for German, where upward-intoned was ('what') is used for open repair initiation and was with falling intonation is used for restricted repair initiation (Selting 1987b; Egbert, Golato \& Robinson 2009), and for Korean, where upward intoned mwe ('what') is an open repair initiator while downward intoned mwe is used for restricted repair initiation (Kim 1999). But intonation is only one way of signalling the functional distinction between an open and restricted use of a what question word. In Murrinh-Patha, a bare form thanggu 'what' is always interpreted as an open RI. Restricted uses of 'what' have more material. In particular, an elaborate system of morphosyntactic noun class markers in this language makes it possible to specify troublesome references down to the noun class, as discussed in $\$ 4.1$ below. Thus in this case, morphosyntactic rather than prosodic resources are used to distinguish two possible functions of the question word in the initiation of repair.

Most languages make available a paradigm of question words, but it is the what-word that is recurrently selected for the function of open repair initiation. Why would some of the other options not be selected? Question words asking for person (who), place (where), reason (why), or time (why) pick out categories that are likely too specific for the purpose of open repair initiation. What-interrogatives, on the other hand, target a large residual category of things. "What you just said" is apparently not so different from "what passed in the distance", which is why both can be asked about using what-interrogatives. Suggestive evidence for this account comes from the fact that several languages feature more extended whatformats. Formats like Chintang them pho 'what REPORTATIVE', Icelandic hvað sagðirðu 'what did you say?', Italian cosa intendi 'what do you mean?', or Siwu so be 'QUOTATIVE what' are built around what-interrogatives (them, hvað, cosa, and $b e$ respectively). The fact that these more elaborate what-based formats exist alongside the single-word formats suggests historical or derivational relationships 
(in the synchronic system, the short and longer formats need not be functionally equivalent of course). Each of the more elaborate what-formats present the question word as the object of an act of saying or intending. In other words, they claim that an act of saying has been registered, but that what it was, or did, or was intended to do, remains unclear. The more compressed what-formats are open to similar interpretations.

One further type of question word we find used in open repair initiation is a manner question word like 'how?'. In German (Selting 1987b), Spanish, and $\neq \bar{A}$ khoe Hail|om (a Khoisan language of Namibia), interrogatives translatable as 'how', as well as those translatable as 'what', both appear in open repair initiation (Enfield et al. 2013). What is the relation between such how- and what-based formats? One possibility is that these open how-formats may point to different types of trouble on the Austin-Clark action ladder (e.g. claiming trouble with the manner in which something was said rather than with what was said), providing for some amount of differentiation even within the open category. If so, they may also solicit different types of repair solutions - an issue we have to flag for future investigation.

\subsection{Formulaic and apology-based forms}

In contrast to the stark minimality of huh? and the directness of what? are formats for open repair initiation that are described as enacting politeness (Kim 1999) or involved in managing social relations (Robinson 2006). Often, but not always, these formulaic forms are "apology-based", i.e., containing a lexical form connected to apologising. Extract 5 exemplifies such a format in Dutch. Jan is adjusting some recording devices in a hair salon, when one of the hairdressers asks for permission to walk through. At line 2, Jan initiates repair with an apology-based form "sorry?", and at line 3 Anne repeats her previous turn.

Extract 5. Dutch (Autosports_83857a)

1 Anne Kan ik er doorheen lopen?

can I EXPL through walk

Can I walk through? ((points to other side of room))

2 Jan Sorry?

Sorry?

3 Anne Kan ik er doorheen lopen?

can I EXPL through walk

Can I walk through? ((points to other side of room))

In a detailed investigation of the apology-based format sorry? in English, Robinson argued that "the apology-based OIR is a practice for communicating repair-initiators' stance that trouble responsibility belongs to themselves" (Robinson 2006: 149). 
Such apology-based forms are also found in French (pardon?) and Italian (scu$s a$ ?). Besides these, we find formats that involve gestures of courtesy. For instance German bitte? 'please' (historically derived from the verb bitten 'to ask for') is not only used to say 'pardon me' and to initiate repair, but more generally to form polite requests of all kinds, like English please (Table 4). The relation of German bitte? 'please' to other open formats is discussed in more detail in $₫ 3.4$ below. $^{6}$

Table 4. Some formulaic and apology-based formats for repair initiation

\begin{tabular}{ll}
\hline Language & Format \\
\hline Dutch & sorry? \\
English & sorry? (Robinson 2006) \\
German & bitte? 'please?' (Selting 1987b; Egbert 1996) \\
Italian & scusa? 'excuse me?' (Giovanni Rossi p.c.) \\
French & pardon? 'pardon?' (Olivier 1985; Beeching 2002) \\
\hline
\end{tabular}

Why would formats like Dutch and English sorry? and German bitte? be useful as open repair initiators? A first feature to note is that they share with other open formats for repair initiation a lack of specificity with regard to the location of the trouble in the prior talk. Like those formats, they can thus be used for interactional troubles at all levels of the Austin/Clark ladder, from the highest to the lowest. In addition to this, apology-based formats are used for the management of responsibility. Responsibility management is relevant because repair can be socially sensitive (highlighting some prior talk by another speaker as problematic and in need of repair) as well as interactionally costly (disrupting the progressivity of the talk). ${ }^{7}$ The formats available include forms that explicitly claim culpability (as in English, Italian, and French) as well as forms that are more generally linked to the expression of courtesy (as in German bitte?). What all of them have in common is that they use linguistic resources connected to doing face-work or politeness (Brown \& Levinson 1987; Arundale 2006). ${ }^{8}$

The responsibility-managing formats known so far are relatively rare in informal conversation. We have attestations of these formats for four of the languages in Table 4 (Dutch, English, German, and Italian), and we have not found such formats in corpora of informal conversation of Siwu, Murrinh-Patha, Chintang, Lao, Russian, and Icelandic. One reason for their rareness may be that the use of a polite or apology-based format highlights a social asymmetry between speakers, and is thus more likely to be found in institutionalised contexts or in conversations between strangers. Indeed the Dutch case cited above is an interaction between strangers. Also, two-thirds of Robinson's English cases come from institutional interaction, leading him to conclude that "the apology-based formats appears to be a relatively uncommon and 'formal' practice of open-class OIR" (Robinson 
2006: 143); ${ }^{9}$ and Selting (1987a) likewise found that the "polite" German format bitte? is predominantly used in government-to-citizen communication and in situations where age differences are large, e.g. in child-adult interaction. We predict that repair initiators managing responsibility or doing face-work will be encountered more frequently in settings and societies where asymmetrical statuses are foregrounded.

\subsection{Open formats as items in a system}

On some occasions, participants may be unable or unwilling to be more specific than claiming the prior turn had some problem(s). These are cases in which the open formats described here are used. Even then, however, the participant initiating repair faces a choice between several options: huh? and what? in most languages, how? in certain languages, as well as formats that manage responsibility in yet other languages. Together, the options within one language form a subsystem of open other-initiated repair.

The coexistence of different items within a system suggests the formats are likely to be not equivalent. However, the non-equivalence of the options is not always easy to show. For instance, several authors have treated English huh? and what? as equivalent for lack of observable interactional differences (Drew 1997: 73; Robinson 2006: 142). Preliminary data from our comparative project suggests that there may be subtle differences in the type of repair solutions engendered at $\mathrm{T}+1$ by interjections versus question words for open other-initiated repair. We have seen in several languages that while both interjection and question word formats often engender some repetition as well as some modification at $\mathrm{T}+1$, interjections appear to engender more unmodified repeats than do question word formats, and conversely, question word formats engender more modifications than do interjections. Even though more collection and analysis is necessary, we take this preliminary finding as pointing to a fruitful locus of future research into formats for open OIR as non-equivalent items in a system.

Research on German offers another view of what may motivate selection of one format over others. The German set of open repair initiators includes $h m / h a ̈ h$ ? 'huh?', was? 'what?', and bitte? 'please?' (Selting 1987b; 1987a; Egbert 1996). Egbert $(1996: 608,613)$ is sceptical about the "folk theory" that these differ in politeness, although she acknowledges that bitte features in politeness marking elsewhere. ${ }^{10}$ Her alternative analysis is that \pm mutual gaze is the decisive factor governing the selection of bitte over other formats: "[t]he selection of [...] German bitte? 'pardon?', indexes that there is no mutual gaze between interlocutors; i.e. there is no common course of action." (Egbert 1996:587; cf. Egbert forthc.). However, there is reason to think that responsibility management is what may be really at stake here. 
Egbert's (1996) findings can be reanalysed as epiphenomena of being engaged in a current joint conversational project (implying a joint responsibility for at least maintaining progressivity of talk). In momentary dissociation (as evidenced by e.g. gaze breaks), an interactant fails to comply with this responsibility and expresses accountability by choosing the polite form. On this account, it may not be gaze (or lack thereof), but rather the taking of responsibility for dissociation and disruption that governs the selection of bitte? over other available formats, at least in German. ${ }^{11}$ Selting (1987c), focussing on other-correction in German institutional interaction, points in the same direction when she observes that attribution of responsibility and consequences for face-management bear heavily on repair initiation and selection of a repair solution.

In the past, studies of repair formats have maintained that there is a "natural ordering" of RI formats on a single dimension - that of strength, or "capacity in locating a repairable" (Sidnell 2010a). The presence of multiple non-equivalent formats within the class of open repair initiators shows that this cannot be the whole story. After all, all open formats are by definition weak or non-specific in their power to locate the repairable. This points to other dimensions of order and other principles of selection. So far, we have seen here that the location or nature of trouble is not the only selection principle; participants initiating repair may also take into account the management of responsibility (Schegloff 2005:468). The role of a third factor, knowledge, in differentiating format designs and guiding format selection will become more apparent in the discussion of restricted formats below.

\section{Restricted formats for repair initiation}

With interjections, single question words, and formulaic or apology-based formats we have exhausted open formats. The set of restricted formats, i.e. formats that zoom in on specific items in the trouble-source, is larger and more internally varied. Formats here are often a mix-and-match of different practices and devices, allowing for different shades of specificity in targeting trouble, different ways of managing responsibility, and different methods for handling knowledge. Despite this variety, the types of linguistic resources used are relatively limited. They consist of content-question words, full and partial repetition, and various types of candidate understandings.

\subsection{Formats involving question words}

All known languages have ways to ask content questions using special interrogative words, which we call here content-question words (Ultan 1978; Cysouw 2004; 
Dryer 2011). Content-question words normatively expect answers pertaining to particular socio-semantic categories. Thus the English interrogative who expects answers that pertain to the category PERSON, where is associated with the category PLACE, what with THING, when with TIME, which with SELECTION, how with MANNER, and why with REASON. Though the categories are illustrated here using English forms, every language has ways to address these categories. Some languages have many distinct interrogatives; other languages have fewer, in which case some categories may be conflated or distinguished only in context (Cysouw 2007).

Content-question words are used for information requests. Previous work on the use of questions in conversational corpora in ten languages has shown that question words are common in initiations of repair, which are, of course, also information requests (Enfield, Stivers \& Levinson 2010). We have already seen the use of single question words in open repair initiation, but the interactional niche where systems of question words really blossom is that of restricted repair initiation. All of the languages we have investigated make extensive use of their question -word systems in restricted other-initiation of repair. In theory, any of the interrogatives can be used for "category-specific" (Schegloff 1997) repair initiation. In practice, the categories PERSON, THING, and PLACE seem to predominate. These are the categories distinguished in most languages (Cysouw 2004; 2007), and also the ones found to be most frequent in conversational corpora (Enfield, Stivers \& Levinson 2010). Languages often feature multiple question-word based formats for other-initiated repair. These may build on different question words (like what and where), or they may employ the same question word in contrasting ways.

An instructive case of contrasting formats built on the same question word has been described for Bequia Creole by Sidnell (2007). This language has at least three who-based formats: huu 'who?', huu X 'who X?' (where X is a repetition of the referring expression used), and huu neem so 'who is named so?'. The formats address three kinds of interactional trouble, which in terms of the present discussion correspond to different rungs on the Austin/Clark action ladder: a problem of hearing, a problem of non-uniqueness of the referring expression, and a recognition failure. The first of the formats, who?, would appear to be open to all of these interpretations. However, it tends to be treated as signalling a hearing problem, and often elicits a straight repeat of the person reference. Why does the format with the most general (least specific) design have such a limited interpretation? This is because of the other formats, which target the higher rungs of the Austin/ Clark ladder. Not selecting one of those more specialised formats implies that the trouble is lower on the ladder; therefore, the selection of who may be understood as conveying a problem of hearing (Sidnell 2007:308). Such implicature effects are inherent in any inventory of linguistic devices that form a contrast set (Horn 
1984; Levinson 2000), and their occurrence in the domain of other-initiated repair underlines the feasibility of a systematic cross-linguistic pragmatic typology.

Here as elsewhere, finer distinctions may be made. German, like English, has a first broad distinction between open was? 'what?' with rising intonation and restricted was. 'what.' with final intonation (Egbert, Golato \& Robinson 2009). But within restricted repair initiation it offers a further distinction: was. 'what.' versus was denn. 'what then'. Although Egbert and colleagues treat these two formats as largely equivalent, they note that the added denn 'then' in the second format may help signal that $\mathrm{T}-1$ and T0 are not contiguous (Egbert, Golato \& Robinson 2009: 128; cf. Egbert forthc.) - a distinction that provides more specificity in locating the trouble.

The morphosyntactic resources of some languages give their what-based interrogatives even greater precision when it comes to pointing out troubles of referential under-specification. For instance, Murrinh-Patha has a series of interrogatives that correspond to most of its ten noun-classes (Blythe 2009:111-3). Most of these derive from the base-form thanggu 'what?'. For example, thanggumi is an interrogative specific to entities pertaining to the vegetable mi-class. Thanggugu is an interrogative specific to the animate $k u$-class (animals, meat, spirits, etc.). As repair initiators, these class-specific interrogatives target a previously mentioned entity pertaining to the given class. Extract 6 exemplifies. Carol and Agnes are telling Mike how Maggie used to be so fearless a hunter that she would put her hand into snake holes to pull out the snakes.

Extract 6. Murrinh-Patha (20110730_JB_video_GYHM100_04)

1 Carol ku pangguy murlakka:, (0.3) merttha damatha.

ku pangguy murlak $-k a$

NC:ANM snake dangerous-TOP

me -art -dha damatha

3SG.S.9snatch.PIMP-get/take-PIMP just

The long dangerous snakes, she just picked them up.

2

(.)

3 Mike na:.

na

TAG

Really!

$4 \quad$ (.)

5 Carol nganaka ranger himself wurrinidha.

nganaka ranger himself wurrini -dha

you_know? ranger him/herself 3SG.S.6go.PIMP-PIMP

She herself was a "ranger"

6

(0.5) 
7 Agnes ngarra weyi kardirdi mebert;

ngarra weyi kardi -rdi

LOC hole 3SG.S.4be.PIMP-put_in

me -be -art

3SG.S.9Snatch.PImp-arm-get/take

Into the \{snake\} hole, she used to put her hand and grab $\{$ it/them $\}$.

$8 \quad(0.5)$

9 Mike thanggugu.

thanggugu

what_animate?

what thing of the animate ku-class?

10

(.)

11 Agnes ku tharinggin $\Gamma \mathrm{ku}:$,

12 Carol

$\mathrm{ku}$ tharringgin ku

NC:ANM king_brown_snake NC:ANM

king brown(s)

13 Laura $L_{k u}$ ngerri ngalla.

$$
\begin{aligned}
& L_{\mathrm{ku}} \text { deadly snake panaya } \\
& \mathrm{ku} \text { deadly snake pana=ya } \\
& \mathrm{NC} \text { :ANM deadly snake } \mathrm{RECN}=\mathrm{CL}
\end{aligned}
$$

$\Gamma>$ pana< thanggugu: : ;

pana thanggugu

RECN what_animate?

deadly snakes, what are they called?

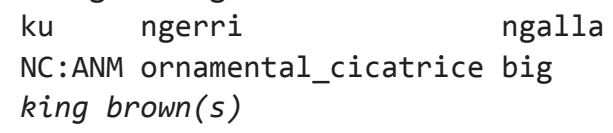

Carol informs Mike at line 1 that Maggie used to just pick up deadly snakes, which Mike acknowledges as noteworthy (line 3). At line 5 Carol likens Maggie to the indigenous rangers (well regarded for their bush-skills). At line 7 Agnes states that she used to put her hand into snake holes and grab the snake(s). At line 9 Mike uses the 'what-animate' interrogative thanggugu to initiate repair on the prior turn. Note, however, that Agnes' reference to the 'hole' weyi does not include an animate $k u$-classifier. That the hole belonged to a dangerous snake is merely implied (i.e. it is zero-referenced at line 7). Thanggugu thus pushes for elaboration of the nominal $k u$-class entity overtly expressed in line 1 as $k u$ pangguy murlak 'long dangerous animate' (normally understood as a variety of venomous snake). Agnes expands on the snake variety by overtly naming $k u$ tharringgin the 'king brown' (Pseudechis australis) at line 11, which, by a different name, is also confirmed by Laura at line 13.

The difference between the three who-based formats of Bequia Creole and the series of noun class-based what-formats of Murrinh-Patha is one of scale more than of kind. In languages with noun class systems such as Murrinh-Patha, there 
are ten or more categories that can be used to narrow down the denotation of the repair initiator - effectively carving up the THING category into subtypes. As these subtypes are culturally salient categories like vegetables or animate things, it is no surprise to see them recruited in formats for restricted other-initiation of repair.

As we have seen above, formats form systems of non-equivalent options. The existence of these options gives participants the freedom to navigate different dimensions, or balance different kinds of concerns. In open OIR, different formats do little to distinguish types of trouble, and appear to exist mainly as different ways of managing responsibility and social relations. In restricted OIR, we see that the different formats allow participants to locate and target the trouble in particular ways. The who-based formats of Bequia Creole characterise the trouble on different levels of the Austin/Clark action ladder. The what-based formats of German target referential underspecification, but may additionally contrast in locating the trouble in directly contiguous vs. more distant prior talk. The question-word based formats specified for noun class of Murrinh-Patha allow even finer-grained focus on troublesome referencing. Table 5 summarises these subsystems, along with the contrastive claims of trouble individual formats embody.

Table 5. Some systems of question word-based formats and their claims of trouble

\section{Formats and their claims of trouble}

Bequia Creole (Sidnell 2007)

who? (hearing)

who $X$ ? (non-uniqueness)

who is named so? (recognition failure)

German (Egbert, Golato \& Robinson 2009)

was. (underspecified reference)

was denn. (underspecified reference + non-contiguity of $\mathrm{T}-1$ and $\mathrm{T} 0$ )

Murrinh-Patha

thanggumi (underspecified reference to entity in the vegetable MI noun class)

thanggugu (underspecified reference to entity in the animate KU noun class)

Why are question words effective devices for initiating repair? At the most general level, questions are next-speaker selection devices (Moerman \& Sacks 1988). They are well-fitted to the other-initiation of repair because they put the ball in the court of the trouble-source producer. In terms of knowledge or epistemics, question words are claims of a K-minus position (Heritage \& Raymond 2005; Heritage 2012): they display that OIR producer is not "in the know" and they request information from the other who is "in the know". Additionally, question words are imbued with semantic contrasts that help to zoom in on the problem and may characterise it in specific ways. Single interrogatives still place some burden on pragmatics - as trouble-source producers must infer the issue at hand - but the 
contrast of the selected format with other available formats helps to locate and characterise the trouble.

Repair initiators that combine question words with other morphosyntactic resources provide even greater focal precision: they have more power to characterise the trouble and (often) more power to locate the trouble. In Murrinh-Patha, the noun class markers on the what-interrogative also appear on the referring expressions themselves $-\mathrm{a}$ form of repetition that allows the repair initiators to tie back directly to the problematic prior references. Similarly, in the Bequia Creole who $X$ format, the $X$ is a repeated person reference. These are examples of the use of repetition in repair initiation, the focus of the next section.

\subsection{Formats employing the repetition of material}

Many formats for the other-initiation of repair employ some form of repetition of material in the trouble-source turn (Jefferson 1972; Schegloff, Jefferson \& Sacks 1977: 368; Wu 2008). Two broad ways of using repetition in repair initiation can be distinguished: those in which repetition helps locate the trouble source by "framing" it (Jefferson 1972), and those in which repetition presents the trouble source itself for repair. Although these may also be combined, we discuss them separately, and then review the contribution made by formats employing repetition to our understanding of the shaping of OIR practices.

In trouble-framing repeats, repetition helps to "frame" or locate the trouble-source item. Formats of this type often employ other techniques besides repetition to point to the trouble source item itself: a question word, intonation, or a candidate understanding (discussed in more detail in the next section). Two examples are found in the following sequence of OIR in Siwu:

Extract 7. Siwu Neighbours_2357030

$1 \mathrm{Aku}$ ile Kədzo kpa?

where PSN go

where'd Kodzo go?

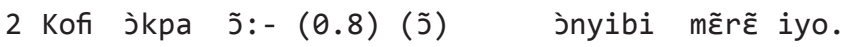

SG:go 3SG.POSS 3SG.POSS sibling \&co house

he is gone to his: (0.8) (his) sibling's lot's house.

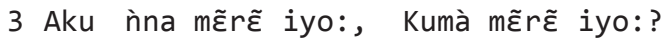

who \&co house, PSN \&co house

who $\{$ se\} Lot's house? Kuma\{'s\} Lot's house?

$4 \quad(1.5)$

5 Kofi ว̃ j̀nyibi

$\mathrm{T}+1$

3SG.POSS sibling

his sibling 
At line 1, Aku asks Kofi where a third person, Kodzo, went. Kofi responds somewhat disfluently with a place reference that is built on a kin-based person reference (line 2). Aku initiates repair at line 3 using a "double", a repair initiation combining two formats (Kim 1999). Both formats in this double utilize repetition of some

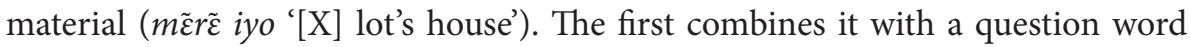
(who) and the second with a candidate understanding (a name). Kofi's repair at line 5 provides a solution that fits in the slot provided by the partial repetition.

Two things are accomplished by the combination of question word and partial repetition in the first part of the double. The question word ina 'who' claims that a person reference was heard but that it was insufficient to achieve reference (as discussed above). The partial repetition of some material from the trouble-source turn pinpoints the trouble source item as being that person reference which occurred just before the repeated part, which on its own would be recognizably in-

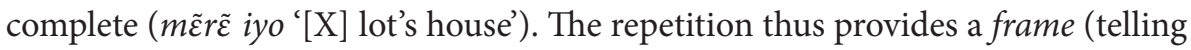
the speaker where to look), and the question word fills in a slot in that frame (telling the speaker what to fix). The second part of the double RI works in a similar way: the repetition again provides a frame, and the person name (Kuma) now supplies a candidate understanding to slot into that frame. ${ }^{12}$ In this sequential context, Kofi's repair solution can be understood as slotting into that same frame, i.e. as effectively replacing the 'who' and the candidate understanding by the person reference 'his sibling's' yielding 'his sibling's lot's house'.

As we see, repetition is a practice that can be combined with devices like question words and candidate repairs to form high-precision ways of pinpointing trouble. ${ }^{13}$ The main function of the partial repetition in the formats discussed thus far is to lead towards, or frame, the trouble source item that is the target of the repair initiation. The types of cues marking partial repetitions as recognizably incomplete (and hence trouble-framing, inviting completion rather than confirmation) are akin to the resources used in "increment initiators" (Lerner 2004): syntactic incompleteness, continuing intonation, and word-final sound stretching.

Another use of repetition in OIR formats works differently. Here, the repetition does not frame the trouble item by reproducing what came with it, but presents the trouble item by reproducing the item itself. In these cases the repeat comes with some form of question marking, which is why it has been labelled questioning repeat (Jefferson 1972). However, in line with our observation above that questioning repeats may also be of the framing type, we propose calling this type of format the trouble-presenting questioning repeat, or trouble-presenting repeat for short. Trouble-presenting repeats are widespread across languages (see for 
example Jefferson 1972; Robinson \& Kevoe-Feldman 2010 for English; Sorjonen 1996 for Finnish; Kim 1999: 155-7 for Korean; Moerman 1977: 874 for Tai/Lue). Here is an example from Siwu.

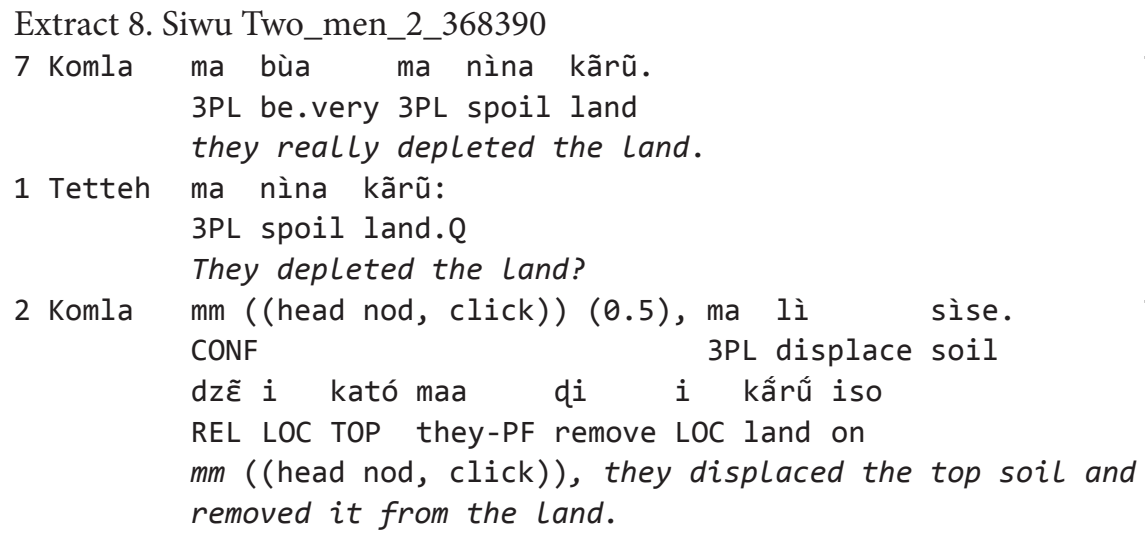

Komla and Tetteh are talking about some farmland that belongs to Komla. At line 1, Komla relates how some of it has been depleted by his family members. Tetteh repeats part of Komla's turn, marking it as a question by utterance-final lengthening. At line 3, Komla follows up with a confirmation ( $\mathrm{mm}$ together with a head nod and a click) and an elaboration, glossing the action of 'depleting the land' as 'displacing the top soil and removing it from the land'.

Tetteh's repair initiation is a trouble-presenting questioning repeat. Komla's repair solution represents the two basic types of repair solutions available in response to trouble-presenting repeats: confirmation (treating the repeat as proffering a candidate understanding) and elaboration (treating the repeat as requesting more information). Some languages distinguish trouble-presenting repeats that request confirmation from those that request clarification. For instance, Wu (2008) describes two Mandarin formats for initiating repair: a "question-intoned repeat" and a repeat suffixed with a final particle $a$. In the data she cites, both are instances of trouble-presenting repeats, but the first engenders clarification, while the second engenders confirmation.

A difference in the type of repair solution provided in response to a repeatformatted repair initiation is not always directly linked to a difference in formatting, but may also be linked to expectations about what is known (Sacks 1992:I:723-9; Robinson 2013). For instance, Robinson showed that partial repetitions of terms clearly known to both speakers never result in clarifications of the terms, but are treated as taking an epistemic position that calls for another type of response, for instance a justification. In terms of the framework of epistemics introduced by Heritage and Raymond (Heritage \& Raymond 2005; Heritage 2012), we can say 
that trouble-presenting partial repetitions presented as K-plus positions (where the speaker initiating repair is evidently "in the know") are treated differently from trouble-presenting partial repetitions presented as K-minus positions (where the speaker initiating repair is evidently not "in the know") - a point also discussed under candidate repairs below.

Why is repetition commonly found in other-initiations of repair? Its primary use in formats for OIR is for locating trouble: either by leading to it or by directly identifying it, or by a combination of both. Merely repeating some material is not enough, however, to signal that repair is being initiated. As Sacks pointed out, repetition is not specific to the machinery of repair - it is a generic and widely used technique for tying back in conversation (Sacks 1992:I:734). Accordingly, we find it used in many different sequential contexts, incorporated in different interactional practices, and implementing different social actions (Sorjonen 1996; Schegloff 1996; Schegloff 1997; Brown 1998; Stivers 2005; Bolden 2009). Turns employing (partial) repetition are hearable as initiating repair only when they combine repetition with other practices involved in OIR formats: question intonation, content-question words, question particles, or candidate understandings. OIR formats employing (partial) repetition can thus be described as combining tying back with interrogation.

In OIR formats employing repetition, how are repetitions that frame trouble sources distinguished from repetitions that present trouble sources? For a partial repetition to be heard as framing a troublesome item, it has to be produced in combination with a slot for it - either in the form of a question word, a substitute candidate understanding, a recognizable incompleteness, or a trouble-presenting repeat. If a repetition does not come with a slot for the troublesome item, it will be heard as presenting the trouble. The importance of cross-linguistic data comes to the fore when we get more specific about the cues for distinguishing troubleframing from trouble-presenting repeats. Whereas past work based on English made a simple distinction between "partial repetition" (taken to be trouble-presenting) and "partial repetition with question word" (taken to be trouble-framing) (Schegloff, Jefferson \& Sacks 1977), and the latter category came to be identified with "questioning repeats" (Jefferson 1972; Sidnell 2010b; Robinson 2012), crosslinguistic data show that the picture is more articulated. Partial repetitions are not always trouble-presenting, and questioning repeats are not exclusively troubleframing. This is why in this paper we distinguish between generic practices like repetition, language-particular devices like a particular interrogative intonation melody, and the formats that are built out of combinations of such practices and devices. 


\subsection{Formats presenting candidate understandings}

At the "strong" end of the traditional scale, that is, with a relatively high capacity to locate the trouble source, Schegloff, Jefferson \& Sacks (1977:368) placed those repair initiators that present a "possible understanding of prior turn", prefixed by y'mean (or variants thereof) in their American English data. Their classical example goes like this:

Extract 9. American English (Schegloff, Jefferson \& Sacks 1977: 368)

1 A Why did I turn out this way.

2 B You mean homosexual?

3 A Yes.

While there are several means other than y'mean to formally mark candidate understandings, a selection of which we will review below, ${ }^{14}$ we observe that the following general repair sequence structure occurs in all languages throughout our cross-linguistic sample:

1 A: turn containing trouble source

2 B: candidate understanding

3 A: confirmation/rejection/elaboration

We will refer to this general format as the candidate repair sequence. Constitutive of this format is that speaker B proffers, at T0, a possible interpretation of (part of) the trouble source turn $(\mathrm{T}-1)$. This interpretation may be a trouble-presenting repeat (discussed in $\$ 4.2$ above) which we call a candidate hearing; or it can display independent inferencing, in which case we refer to it as a candidate understanding. By presenting a candidate understanding, B points to a potential trouble source, thus initiating repair, and at the same time offers a potential repair solution for confirmation. Despite an enormous range of variation in the internal make-up of candidate understandings in our sample, they all have in common that they are marked with one or more linguistic devices that characterise interrogation in the respective language. Among these marking devices, what comes into view is first and foremost interrogative prosody. This often translates as a rising contour akin to try-marking (Sacks \& Schegloff 1979). However, here as in other formats, the crucial factor is alignment with the interrogative system of the language, not an upward intonational trajectory by itself. In the light of the cross-linguistic observations laid out in the sections above, it comes as no surprise that we find candidate understandings carrying a downward intonation contour in some languages of our sample where such contours are more commonly associated with interrogativity, notably Icelandic and Cha'palaa. 
Traditionally, interrogative intonation is often associated with a relative knowledge deficit of the speaker vis-à-vis the addressee - in technical terms, with a K-minus position (Heritage \& Raymond 2005). However, interrogative intonation is only one of several possible ways of marking the K-minus position from which a candidate understanding arises. Other methods derive from lexical and morphosyntactic resources relating to question construction for the respective languages. Let us review some examples.

Together with rising intonation, the English $y^{\prime}$ mean serves as a device for epistemic downgrading: it mitigates the assertiveness of an utterance by indicating that what follows is not claimed as a statement of fact but rather as an inference about another person's state of mind. Some languages have dedicated particles for expressing candidate status (or inferential evidentiality) which function in similar ways. Consider the following example from Lao, in which the particle vaa 3 is used. This particle signals that the proposition just expressed is the result of a thought process awaiting ratification (Enfield 2007:45f.). ${ }^{15}$

Extract 10. Lao (INTCN_030806a_11.40)

$1 \quad$ A mèèn1 phaj3 paj3 haa3 nòò-maj4 khùù2 maa2 vaj2 COP who go seek bamboo_shoot why come quick thèè4 niф

really TOP

Who's been collecting bamboo shoots and returned so early?

$B$ juu1 naj2 thaj2 han5 vaa3

be_at in sack DEM.DIST QPLR.INFER

In that sack you mean?

3 A qee5

yeah

Yeah

While the Lao particle combines multiple functions in a compact form, possessing a grammatical category of evidentiality or epistemicity or a dedicated candidate particle is not a prerequisite for morphosyntactic candidate marking. In principle, any element that regularly derives polar questions from declarative utterances lends itself to proffering a candidate from a K-minus position, since they all display a subordinate epistemic stance. After all, as Bolinger noted, any polar question "advances a hypothesis for confirmation" (Bolinger 1978: 104). Thus in Russian we find candidate understandings marked by means of appending the affirmative particle $d a$ 'yes' as a question tag (Extract 11): ${ }^{16}$

Extract 11. Russian (20110813_Sisters_789530)

1 A a tam ana byla $v$ Navagornam 
B u papy da?

at father:GEN yes

At $\{$ her $\}$ father $\{$ 's place\}, yes?

3 A u babushki.

$\mathrm{T}+1$

at grandmother:GEN

At $\{$ her $\}$ grandmother $\{$ 's place\}.

What are the design features of candidate understandings such that they are useful formats for other-initiation of repair? The English, Lao, and Russian examples illustrate the underlying properties constitutive of candidate repairs. ${ }^{17}$ Action-wise, candidate understandings attempt an independent claim at the issue in question (the repairable) and seek to have this claim confirmed. Logically speaking, the knowledge gap that this repair structure needs to bridge is twofold: it comprises a propositional part (a claim) ${ }^{18}$ and a truth-value part (marking the claim as a hypothesis). In Extract 11, for instance, the speaker initiating repair provides a candidate claim ('at \{her\} father\{'s place\}'), together with a prompt for the other to assess its truth value (da? 'yes?').

With regard to characterising the trouble, candidate repairs can only be employed if at least the lower two rungs of the Austin/Clark action ladder have been successfully passed: producing a candidate understanding presupposes having heard what was said and having processed and identified the words. Employing a candidate repair therefore signals that the trouble was with understanding or with adequately integrating the trouble source into the epistemic background (cf. Selting 1987b; Egbert 2009). It follows that in candidate repair sequences, the knowledge distribution of participants is different from other repair formats. The epistemic cline between interlocutors is usually less steep here: even though B has less knowledge than $\mathrm{A}$, the knowledge should be greater than zero. The different epistemic alignment of the interlocutors determines what trajectories the repair sequences may take (Robinson 2012).

By closer alignment of the interlocutors in the dimensions of epistemics and responsibility, candidate repair sequences can proceed without attracting as much attention. The person proffering a candidate understanding not only demonstrates that he or she has been following the course of the conversation in general (as does anyone initiating repair), but also that there are no troubles further down the Austin/Clark ladder (which would require serious backtracking) and, moreover, that he or she has been actively thinking and following along. The resulting flatter epistemic cline can then be levelled with less effort - for instance by responding with a minimal confirmation when the candidate understanding turns out to be correct. This, in turn, permits sequences in which the repair is less obstructive to the progressivity of the conversation, and thus compatible with a larger range of joint undertakings in which the repair does not take centre stage. In fact, thanks to 
flexibility in candidate construction and identification of potential trouble sources, and to its resemblance to conversational practices with less disruptive characteristics such as polar questions, a candidate repair may earn its name not only by proffering a candidate understanding, but by being ambiguous between trying to accomplish a repair and doing something else. ${ }^{19}$

\section{Trouble, knowledge and responsibility}

We have surveyed formats for initiating repair across languages. Every language offers a range of options, but the range is not indefinite, and the formats on offer display strong similarities across languages. Throughout, we have drawn attention to the way in which generic practices such as repetition and questioning are combined with language-specific devices to form particular formats for initiating repair. The common recurrence of particular types of practices and devices across languages makes visible some overarching factors that appear to be at play. On the basis of the present study, we distinguish three particularly evident concerns: trouble, knowledge, and responsibility.

\subsection{Trouble}

The design of repair formats across languages provides evidence that locating and characterising TROUBLE is an important concern in the initiation of repair. This is of course unsurprising insofar as repair has always been described as an organisation for dealing with problems in conversation. However, formats and the inferences they generate (e.g. claiming trouble or the lack of it) can be exploited by interlocutors and may become means to ends that go further than simply correcting misunderstandings.

We have used the Austin/Clark action ladder to describe the different levels of speaking and understanding at which trouble may originate (Austin 1962; Clark 1996; and see Selting 1987a; Clark \& Schaefer 1987; Enfield 2013). Overall, we find that every language provides its users with a range of options for locating trouble in this possibility space - options varying in granularity or strength as suggested in the original proposal in SJS (1977). At the most generic level, all languages in our sample offer at least two remarkably similar formats for signalling that there is trouble in a previous turn while leaving open what or where it is exactly: the interjection and the question-word based formats for open OIR (Enfield et al. 2013). Beyond these open formats, all languages furthermore provide a range of restricted formats that offer more specific localization of trouble within a troublesource turn-constructional unit. In all languages in our sample, we find three basic 
techniques for locating trouble, which can occur on their own but also can be combined in formats. One technique is to hook into the morphosyntactic resources of the language, especially its system of question words, to pinpoint particular socio-semantic categories of trouble sources. A second technique is to use repetition for tying back to lead to the trouble source (as in trouble-framing repeats) or to identify it (as in trouble-presenting repeats). A third is to supply a candidate understanding: this not only locates the trouble source (using paradigmatic or syntagmatic cues), but goes one step further in proposing a possible solution.

Differences surface where languages offer different resources for pinpointing trouble. For instance, as we saw, some languages may combine question words with noun class morphosyntax for even finer-grained directions to locate the trouble; and in some languages, specialised formats may deal not just with locating but also characterising trouble - e.g. the 'who?' and 'who is named so?' formats of Bequia Creole. ${ }^{20}$ Across languages, systems of formats for repair initiation offer speakers a range of possibilities for locating and specifying trouble.

\subsection{Knowledge}

The question of what we know and what we think others know is always relevant in conversation (Goffman 1971; Kamio 1994; Heritage \& Raymond 2005; Heritage 2012), but perhaps especially so when trouble surfaces. The clearest sign of this is the fact that we find that questioning devices pervade every single format type across all languages in our sample: the person initiating repair tends to do so by claiming a K-minus position relative to something that was said earlier. This is one of the driving forces in the structuring of sequences of other-initiated repair; as noted, questions are next-speaker selection devices that put the ball back in the court of the trouble source producer.

But the question of epistemics pervades formats for initiating repair in other ways, too. By choosing certain formats over others, participants claim different levels of "grasp" of the trouble source: ${ }^{21}$ a huh? interjection displays no grasp whatsoever of the trouble source, a partial repetition demonstrates at least what was heard, and candidate understandings demonstrate different sorts of knowledge. This is why candidate repairs shade into other-correction (SJS 1977:378-81), and why we find other-initiated repair bound up in disagreement-implicative sequences (Schegloff 2007: 102-4,151-5): a repair initiation takes issue with some previous saying and may therefore be heard as prefiguring disagreement. Differences in the knowledge distribution of participants are thus another dimension along which repair formats can be organised. 


\subsection{Responsibility}

Our choices in social interaction have consequences that are not just informational but also relational (Hinde 1976; Stivers, Mondada \& Steensig 2011; Enfield 2013). Questions of responsibility inevitably attend the signalling of trouble and its resolution. Formats for the other-initiation of repair offer varied ways to deal with this responsibility. For instance, an open format like huh? claims some unspecified trouble and thereby leaves the question of responsibility quite open, whereas a restricted format like who? may be taken to point out a recipient-design error and thereby place the responsibility more clearly on the trouble-source speaker. It is no surprise then that we find that open formats may be preferred over restricted formats for politeness reasons (as in Korean, Kim 1999), and that we sometimes find restricted formats prefaced by apologies (in British English, Schegloff 2005). Another sign of the importance of responsibility is the existence of apology-based formats in several languages: formats by means of which the person initiating repair can explicitly claim responsibility for the trouble.

Responsibility is also relevant with respect to repair solutions, as we see in candidate understandings, where repair initiators take it upon themselves to not just point out a problem, but also to supply (and thereby indicate their willingness to share in the responsibility for) a possible solution. The balance between responsibility for trouble and for solution can even be inverted when a candidate understanding can be understood as suggesting a "better" form; this is where the original speaker becomes fully responsible for trouble and the one initiating repair for its solution, and where next turn other-initiated self-repair shades into other-repair or other-correction. Like the matters of locating trouble and handling knowledge, then, responsibility is not an all-or-nothing affair: different formats afford different possibilities to shift and share responsibility across participants.

\section{Formats and flexibility}

Central to some of the most enduring conceptions of language is the idea that their structure can be understood as interlocking systems of signs (Gabelentz 1891; Sapir 1921; Firth 1930; Halliday 1970). That structure and systematicity can be found in lexical and grammatical systems has been clear from the earliest grammatical and typological work; that it may also be found at the level of conversational structure and interactive language use is a more recent realisation. We have described here some of the structural characteristics of systems of formats for other-initiation of repair across languages. With the knowledge in mind of how items within these 
systems relate to each other, it is useful to consider how selection of one format over others may be done, and what it may imply.

From the point of view of the language user, any organisation of alternative resources makes selection possible (Halliday 1971). A fundamental insight of conversation analysis is that the selection of resources in interaction is not merely done in mechanistic ways but that the possibility of selection affords strategic uses (Sacks 1992). In other-initiation of repair, the use of a certain format entails certain claims (and therefore implies certain stances) about the nature of the trouble, the distribution of knowledge, and the locus of responsibility.

Already in the first systematic study of repair in English, SJS (1977:369n15) noted that the relative "strength" of OIR formats in terms of their capacity to locate TROUBLE provides one way of ordering, and hence one ground for selection. Here we have seen that there are at least two more relevant dimensions, or grounds for selection. Formats can also be ordered with respect to RESPONSIBILITY, from formats that simply point out a problem with someone's prior turn to formats that explicitly claim that responsibility for the trouble lies with the repair initiator; and they can be ordered with respect to states of KNOWLEDGE they imply.

The choice of one format over others potentially privileges one or more of the concerns over others, and this can be seen as a way of doing something. For instance, a desire to be as specific as possible in locating trouble may clash with a desire to manage responsibility: in such a case it may be preferable to choose an open format like ney? 'yes?' over a more specific format (Kim 1999). Or a preference for "stronger" over "weaker" formats may clash with a social norm about knowledge in relation to status: for instance, caregivers may avoid the use of candidate understandings towards infants in a society where infants are not seen as personalities with their own intentions (Ochs 1984).

This multidimensional view of the selection of formats for initiating repair presents a solution to the recurrent question of how formats are ordered with respect to one another. The idea of one "natural ordering" based on "strength" and a "preference for stronger over weaker initiators" (Schegloff, Jefferson \& Sacks 1977:369) has been widely accepted (e.g. Clark \& Schaefer 1987; Suzuki 2010; Sidnell 2010a). Based on this idea, Clark \& Schaefer (1987) proposed the "strongest initiator rule": in repair, participants should always choose the strongest initiator that is available for the purpose. Since then, however, several alternative loci of order have surfaced. Selting $(1987 a ; 1987 c)$ found that the preference articulated by SJS (1977) and Clark \& Schaefer (1987) may be reversed in German government-to-citizen communication. Svennevig (2008) proposed a preference for trying the easiest (least complicated, least sensitive) solution first, finding that problems of acceptability and understanding may often initially be addressed as hearing problems in a mixed corpus of informal and institutional interaction in 
Norwegian. Schegloff (2005) and Robinson (2006) showed that trouble responsibility could be one ground for selecting one format over another in English conversation. Egbert (forthc.) documents another deviation from the preference for stronger over weaker initiators: positioned questions, the formatting of which is not dictated merely by strength but by sequential remoteness.

These diverse accounts of other-initiated repair support the thesis that the selection of a format for other-initiation of repair is not always dictated by a single principle (be it Clark \& Schaefer's "strongest initiator rule" or Svennevig's "trying the easiest solution first") but that it may involve multiple, sometimes competing principles. In every language, the inventory of formats for initiating repair supplies speakers with a system of possibilities to navigate these matters. This is what makes repair initiation not a mere mechanical operation but a choice with interactional, informational, and interpersonal consequences.

Although trouble, knowledge and responsibility are the concerns identified here as most important, they are not necessarily the only relevant ones. They operate against the background of other principles (such as a preference for progressivity, Stivers \& Robinson 2006) and they may be complemented by other principles less evident in our current cross-linguistic sample. What other selection principles might be found and how general or context-specific are they? Are they ranked differently across settings or societies, as evidenced by which formats are available and how the available formats are used? How do the selection principles interrelate? Is there a default selection principle (as argued by Egbert forthc.; and perhaps implicitly by SJS 1977)? Future research will be able to address these questions.

\section{Conclusions}

Given that people sometimes have differing interactional projects, different knowledge states, sometimes start speaking at the same time, are prone to distractions from within their surroundings, etc., it is surprising how much of conversation proceeds without major hitches. Far from showing structural deficits in performance vis-à-vis competence (Chomsky 1965:4), conversational repair amounts to a sophisticated traction control mechanism for building and maintaining intersubjectivity in interaction (Schegloff 2006; Hayashi, Raymond \& Sidnell 2013).

Every other-initiation of repair may manage at least three things at once: characterising trouble, managing responsibility, and handling knowledge. We hypothesise that these concerns have come to shape repair practices across languages because they are always potentially interactionally relevant when repair is initiated. Table 6 sketches how different types of formats have different implications with respect to trouble, responsibility, and knowledge. 
Table 6. Some types of formats and their implications about trouble, responsibility, and knowledge

\begin{tabular}{|c|c|c|c|}
\hline & Trouble & Responsibility & Knowledge \\
\hline Huh? & $\begin{array}{l}\text { Claims but does not locate } \\
\text { or characterise trouble }\end{array}$ & $\begin{array}{l}\text { No on-record position } \\
\text { on responsibility (but A's } \\
\text { responsibility is implied) }\end{array}$ & Claims no knowledge \\
\hline Sorry? & $\begin{array}{l}\text { Claims but does not locate } \\
\text { or characterize trouble }\end{array}$ & $\begin{array}{l}\text { On-record claim of B's } \\
\text { responsibility }\end{array}$ & Claims no knowledge \\
\hline $\begin{array}{l}\text { [Trouble- } \\
\text { presenting } \\
\text { repeat] }\end{array}$ & $\begin{array}{l}\text { Claims and locates } \\
\text { trouble; characterizes it } \\
\text { as higher up Austin/Clark } \\
\text { ladder than hearing. }\end{array}$ & $\begin{array}{l}\text { No on-record position on } \\
\text { responsibility }\end{array}$ & $\begin{array}{l}\text { Displays knowledge of } \\
\text { what was heard but pro- } \\
\text { fesses lack of knowledge as } \\
\text { to how to interpret it }\end{array}$ \\
\hline Who? & $\begin{array}{l}\text { Claims, locates, and char- } \\
\text { acterises trouble }\end{array}$ & $\begin{array}{l}\text { No on-record position on } \\
\text { responsibility }\end{array}$ & $\begin{array}{l}\text { Displays that a person } \\
\text { reference was heard; claims } \\
\text { that it was insufficient to } \\
\text { achieve recognition }\end{array}$ \\
\hline $\begin{array}{l}\text { [Candidate } \\
\text { under- } \\
\text { standing] }\end{array}$ & $\begin{array}{l}\text { Claims, locates, and char- } \\
\text { acterises trouble }\end{array}$ & $\begin{array}{l}\text { No on-record position on } \\
\text { responsibility for trouble, } \\
\text { but takes responsibility for } \\
\text { solution }\end{array}$ & $\begin{array}{l}\text { Displays an interpretation } \\
\text { of something thereby en- } \\
\text { tailed to have been heard }\end{array}$ \\
\hline
\end{tabular}

The question of how we build and maintain mutual understanding in conversation is at an interdisciplinary crossroads, where the study of human sociality meets the modelling of dialogue, and the study of conversational structure meets linguistic typology. By mapping out the linguistic resources used in the domain of otherinitiated repair and developing explanations for cross-linguistic similarities, our study contributes not only to a better understanding of repair and mutual understanding in conversation, but also to the growing field of comparative studies of conversational structure, called by such names as pragmatic typology, typology of language use, conversational typology, or cross-cultural pragmatics (Dingemanse \& Floyd in press).

We have developed a pragmatic typology of formats for other-initiation of repair across languages. Across languages, the matters of TROUbLE, KNOWLEDGE, and RESPONSIBILITY are relevant in the other-initiation of repair. As ever-present concerns, they provide the degrees of freedom within which the linguistic variation in the domain of repair plays out, accounting for the remarkable cross-linguistic similarities in the inventories of formats we have discussed. As alternative selection principles, they provide participants in conversation with flexible means for achieving mutual understanding, handling the distribution of knowledge, and managing social relations. 


\section{Acknowledgements}

This paper presents findings from a cross-linguistic study of other initiated repair conducted in the research group on Human Sociality and Systems of Language Use at the Max Planck Institute for Psycholinguistics in Nijmegen. We thank Nick Enfield for making this research possible, all our colleagues in the OIR project for supplying input in group discussions, Jeff Robinson for commenting on an early version, and two anonymous reviewers for Studies in Language for providing constructive feedback on the manuscript. The research was funded by the European Research Council grant 240853 (Dingemanse \& Blythe), Australian Research Council grant DP110100961 (Blythe), and the Max Planck Society for the Advancement of Science (Dirksmeyer). Table 1 in $\$ 1$ lists the languages this study draws on, along with the researchers who have contributed examples of formats. The inventory of formats in these languages is documented in more detail in a forthcoming special issue of Language Sciences.

\section{Abbreviations}

ACC: accusative; COP: copula; DEM.DIST: distal demonstrative; EX: exclusive of the addressee; EXPL: null expletive; EXIST: existential; F: feminine; FUT: future; GEN: genitive; HES: hesitation; I: "I" noun class (Siwu); IMP: imperative; IMPV: imperfective viewpoint aspect; INTJ: interjection; M: masculine; MoBr: mother's brother; NC:ANM: "animate" noun class; NEG: negator/negation; NOM: nominative; OIR: (next turn/position) other-initiation of repair; PFV: perfective viewpoint aspect; PIMP: past imperfective; PST: past tense; PCL: particle; POSS: possessive; PSN: personal name; PTCP: participle; PL: plural; Q: question marker; QPLR.INFER: inferential polar question; RECN: recognitional demostrative; RI: repair initiation; S: subject; SG: singular; STRI: same-turn initiation of repair; TAG: tag particle; TCU: turn-constructional unit; TOP: topic.

\section{Notes}

1. Other-initiated repair is a vast domain. We do not attempt to cover here such aspects of its organisation as the role of visible behaviour; the selection and ordering of formats in more extended OIR sequences; the use of repair formats to deliver special actions over and above mere repair; and the role of prosody in OIR (Selting 1996; Curl 2005). Within the OIR sequence, our focus here is on formats of repair initiators (which occur at the T0 position in our schematic representation of the sequence), although a comprehensive cross-linguistic study of other-initiated repair will eventually have to include the formats of repair solutions ( $\mathrm{T}+1$ position) and their uptake ( $\mathrm{T}+2$ position) as well.

2. Although independently developed, the 'addressee actions' in the Austin/Clark action ladder bear some similarity to four levels of understanding offered by Selting (1987a: 167; 1987b: 131ff.) in an analysis of repair in German. Selting's addressee-centered model of four levels of understanding gives rise to four types of trouble: 'acoustic', 'reference,', 'local meaning', and 'local expectation'. 
3. Here, as elsewhere in the paper, the provided names are pseudonyms.

4. Tables like this are used throughout the paper to illustrate salient points. Rather than including long lists we attempt to illustrate our claims using examples from diverse languages. If no source is cited, the data is from our own research.

5. Although what-based formats for open OIR are widely used, they are not universal. Enfield et al. (2013) report that in two languages in their 21 language sample (Tzeltal and Yélî Dnye), the use of question words corresponding to what for open repair has not been observed.

6. Bitte (without the rising intonation contour) serves a variety of other interactional functions in politeness-sensitive environments, such as those where speakers of English might use here you are or you're welcome.

7. That the matter of responsibility or culpability is relevant is also shown by the fact that the speaker of the trouble can claim responsibility for it after an other-initiation of repair (Schegloff 2005: 469).

8. A type of RI format that has been claimed to enact politeness is Korean yey? (with variant $n e y$ ?). In Korean, "polite forms like yey? or ney? [...] are used when the interactants are not close to each other and/or when the speaker is younger than the interlocutor" (Kim 1999: 145). These forms are based on "response tokens used as an affirmative answer meaning 'yes" (Kim 1999: 145), overlaid with a questioning intonation contour, just like the interjection and apology-based formats discussed above. A similar open RI format has been described for Japanese by Suzuki (2010), though without claims about politeness. Formats like this appear to work in a slightly more indirect way than apology-based formats, possibly by turning the affirmative token (a structurally preferred second pair part) into a marked form by overlaying it with a questioning intonation contour. The transformation of the unmarked form would signal that something unusual is at hand as per Levinson's (2000) markedness heuristics, and the questioning intonation would point the interlocutor to the necessary action by simultaneously signalling a knowledge deficit on the part of $\mathrm{B}$ and returning the floor to $\mathrm{A}$.

9. Likewise, in a collection of 1300 cases of OIR in English, Schegloff finds only 30 apologybased forms, and notes that " 23 (over 75 percent) come from conversations in an institutional context" (2005:471).

10. Native speakers of German report that parents instruct their children that häh? and was? are quite rude and unrefined repair initiators, and that one should say (wie) bitte? instead - in much the same way that they insist their children include bitte in a request to make it more polite/less impositional. More generally, when a language has a range of open formats, native speakers often report them to be ordered according to politeness (Selting 1987b for German; Olivier 1985 for French; Kim 1999 for Korean). It is an open question to what extent such folk judgments reflect and inform actual usage within and across languages.

11. This responsibility would be relatively higher in purpose-driven, more institutionalized dyadic conversations than in casual multi-party interaction (where even speaker selection is less clear), which would explain why Egbert found a lot more bitte? in her telephone data than in videotaped dinner-table conversations with multiple people (Egbert 1996:607-8). 
12. Both formats in this double may also deal with a possible ambiguity relating to vowel qualities: the third person possessive pronoun $\tilde{z}$ is very similar in form to the first person possessive pronoun $\tilde{u}$.

13. The partial repetition frame may repeat words that precede and follow the slot specified by the question word, as in the following excerpt from a case discussed in Schegloff (2000:226):

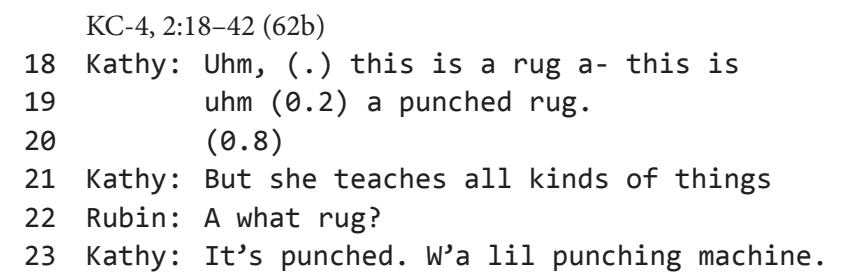

14. Also note that y'mean may serve functions above and beyond what we discuss in this section, for instance, signalling non-contiguity of trouble source and repair initiation (Benjamin 2012).

15. Whilst the English y'mean is preposed, it is more common cross-linguistically for polar interrogative markers to be post-posed (Dryer 2011).

16. Extract 11 also illustrates the use of what Sacks called an appendor question: B's line 2 can be heard as being appended to the syntactic structure of A's turn. As Sacks (1992:657) noted, appendors can add the missing part necessary for interpreting a previous utterance as delivering a particular action, e.g. appending 'please' to a command retroactively turns it into a request.

17. Due to limitations of space, we are not able to detail a number of further variations on this theme, one of which includes disjunctives: alternative questions like the one sitting or the one walking? or elliptical forms like at home or?. Such disjunctives, by virtue of the fact that they recognise other possibilities and leave open the $\mathrm{T}+1$ position for responses of different kinds (confirmations-by-repetition as well as further clarifications), reduce the risk of rejection and don't put either party all too directly on the spot. The principal openness of combining an independently-inferred candidate with almost anything else in a disjunction can turn an alternative question into a bridge in many directions. For instance, in Chintang, elo manchi 'or isn't \{it\}' points in the direction of English tags, while 'five lakh or how much?' connects candidate repair with an alternative question format. That 'or' also features as a question tag in other languages near and far (such as Nepali ki? and German oder?) suggests that the interactional utility of such structures extends beyond the boundaries of individual languages, and indeed beyond the boundaries of repair.

18. Where the candidate understanding does not itself express an entire proposition, it can be heard as an ellipsis of co-textually or contextually retrievable material, together with which it becomes truth-apt.

19. It naturally follows that sequences featuring candidate understandings may bear certain structural resemblances to what Schegloff (1996) termed "confirming allusions". An assumption underlying A's $\mathrm{T}-1$ is inferred by B and explicated in T0, putting it up for confirmation. Confirmation is provided in $\mathrm{T}+1$ by repeating appropriate material from $\mathrm{T} 0$ (with deictic modifications etc. as required) and expanding the turn, which paves the way for seamless continuation of the conversation. Whether or not this qualifies as an instance of repair, and under what 
criteria, or whether it should rather be treated as something else, is virtually immaterial here. What counts is that this format provides a quick and efficient way to calibrate interactional common ground (Clark \& Marshall 1981), and thus maximises the intersubjectivity and progressivity of the conversation. Assumptions can be brought to light at the interactional surface and held to the test as to whether interlocutors share a common understanding with respect to this issue.

20. Although for practical reasons in our discussion the presented formats have fallen on either side of an open/restricted divide, the matter of trouble-source localisation is potentially distinct from trouble-source characterisation, and this provides a further dimension of structure to the problem/possibility space. For instance a format like Italian cosa intendi? 'what do you mean?' may not localise the trouble any more specifically than cosa 'what?', but it may characterize the trouble as higher up the Austin/Clark action ladder insofar as it implies that the problem is not one of hearing or attending, but more one of understanding intentions. Probing the difference would require a careful study of how such formats are treated at $\mathrm{T}+1$.

21. "Strength" in the sense of "capacity to "locate' a repairable" (SJS:369n15) and "grasp" in the sense of "grasp of the meaning of the trouble-source" (Kim 1999:152) have occasionally been conflated. The reason for this is that they may point in the same direction: a question-word based format like who? points out some trouble with a previous person reference and, at the same time, displays at least some grasp of the trouble (namely that it was a person reference), whereas an interjection like huh? may do neither. However, the two do not necessarily coincide. For instance, a trouble-framing repeat may locate a repairable very precisely without claiming much grasp of it, while huh? (when it reveals trouble in understanding not words or their meanings, but with the action some turn is doing) may not locate anything specific within the trouble source turn (and thus be "weak" in locating) precisely because everything at these lower levels was grasped. The confusion is partly caused by conflating repairable with trouble-source TCU locating part of the trouble-source TCU does not necessarily entail grasp of the repairable itself, for reasons detailed in our discussion of the Austin/Clark action ladder in $\$ 2$ and of the uses of repetition in $\$ 4.2$.

\section{References}

Arundale, Robert B. 2006. Face as relational and interactional: A communication framework for research on face, facework, and politeness. Journal of Politeness Research. Language, Behaviour, Culture 2(2). 193-216. DOI: 10.1515/PR.2006.011

Austin, J. L. 1962. How to do things with words. Oxford: Clarendon Press.

Beeching, Kate. 2002. Gender, politeness and pragmatic particles in French, Pragmatics \& Beyond New Series, vol. 104. Amsterdam: John Benjamins. DOI: 10.1075/pbns. 104

Benjamin, Trevor. 2012. When problems pass us by: Using 'You Mean' to help locate the source of trouble. Research on Language \& Social Interaction 45(1). 82-109. DOI: 10.1080/08351813.2012.646742

Benjamin, Trevor. 2013. Signaling trouble: On the linguistic design of other-initiation of repair in English conversation. Groningen: University of Groningen dissertation.

Blythe, Joe. 2009. Doing referring in Murriny Patha conversation. Sydney: University of Sydney dissertation. 
Du Bois, John W., Stephan Schuetze-Coburn, Danae Paolino \& Susanna Cumming. 1993. Outline of discourse transcription. In Jane A. Edwards \& Martin D. Lampert (eds.), Talking data: Transcription and coding methods for language research, 45-89. Hillsdale, NJ: Lawrence Erlbaum.

Bolden, Galina B. 2009. Beyond answering: Repeat-prefaced responses in conversation. Communication Monographs 76(2). 121-143. DOI: 10.1080/03637750902828446

Bolinger, Dwight L. 1978. Yes-no questions are not alternative questions. In Henry Hiz (ed.),Questions, 87-105. Dordrecht: Reidel. DOI: 10.1007/978-94-009-9509-3_3

Brown, Penelope. 1998. Conversational structure and language acquisition: The role of repetition in Tzeltal. Journal of Linguistic Anthropology 8(2). 197-221. DOI: 10.1525/jlin.1998.8.2.197

Brown, Penelope \& Stephen C. Levinson. 1987. Politeness: Some universals in language usage. Cambridge: Cambridge University Press.

Chomsky, Noam. 1965. Aspects of the theory of syntax. Cambridge: M.I.T. Press.

Clark, Herbert H. 1996. Using language. Cambridge: Cambridge University Press. DOI: 10.1017/ CBO9780511620539

Clark, Herbert H. \& C. R. Marshall. 1981. Definite reference and mutual knowledge. In Aravind K. Joshi, Bonnie L. Webber \& Ivan Sag (eds.), Elements of discourse understanding, 10-63. Cambridge: Cambridge University Press.

Clark, Herbert H. \& Edward Schaefer. 1987. Collaborating on contributions to conversations. Language and Cognitive Processes 2(1). 19-41. DOI: 10.1080/01690968708406350

Curl, Traci S. 2005. Practices in other-initiated repair resolution: The phonetic differentiation of 'repetitions'. Discourse Processes 39(1). 1-43. DOI: 10.1207/s15326950dp3901_1

Cysouw, M. 2004. Interrogative words: An exercise in lexical typology. Presentation presented at the Bantu grammar: Description and theory workshop, February 13.

Cysouw, Michael. 2007. Content interrogatives in Pichis Ashéninca: Corpus study and typological comparison. International Journal of American Linguistics 73(2). 133-163. DOI: $10.1086 / 519056$

Dehé, Nicole. 2009. An intonational grammar for Icelandic. Nordic Journal of Linguistics 32(1). 5-34. DOI: $10.1017 /$ S0332586509002029

Dingemanse, Mark \& Simeon Floyd. In press. Conversation across cultures. In N. J. Enfield, Paul Kockelman \& Jack Sidnell (eds.), Cambridge handbook of linguistic anthropology. Cambridge: Cambridge University Press.

Dingemanse, Mark, Francisco Torreira \& N. J. Enfield. 2013. Is 'Huh?' a universal word? Conversational infrastructure and the convergent evolution of linguistic items. PLOS ONE. DOI: 10.1371 /journal.pone.0078273

Drew, Paul. 1997. 'Open' class repair initiators in response to sequential sources of trouble in conversation. Journal of Pragmatics 28. 69-101. DOI: 10.1016/S0378-2166(97)89759-7

Dryer, Matthew S. 2011. Position of interrogative phrases in content questions. In Matthew S. Dryer \& Martin Haspelmath (eds.), The world atlas of language structures online. Münich: Max Planck Digital Library. http://wals.info/chapter/93.

Egbert, Maria. Forthcoming. Selection principles for other-initiated repair turn formats - an answer from positioned questions. In John Heritage, Gene H. Lerner \& Geoffrey Raymond (eds.), Finding the universal in the particular: Festschrift for Emanuel A. Schegloff on his 70th birthday. Blackwell.

Egbert, Maria. 1996. Context-sensitivity in conversation: Eye gaze and the German repair initiator bitte? Language in Society 25(4). 587-612. DOI: 10.1017/S0047404500020820 
Egbert, Maria. 2009. Der Reparatur-Mechanismus in deutschen Gesprächen. Mannheim: Verlag für Gesprächsforschung. http://www.verlag-gespraechsforschung.de/2009/egbert.htm.

Egbert, Maria, Andrea Golato \& Jeffrey D. Robinson. 2009. Repairing reference. In Jack Sidnell (ed.), Conversation analysis: Comparative perspectives, 104-132. Cambridge: Cambridge University Press. DOI: 10.1017/CBO9780511635670.005

Enfield, N. J. 2007. A grammar of Lao. Berlin: Mouton de Gruyter. DOI: 10.1515/9783110207538

Enfield, N. J. 2013. Relationship thinking: Agency, enchrony, and human sociality. Oxford: Oxford University Press. DOI: 10.1093/acprof:oso/9780199338733.001.0001

Enfield, N. J., Mark Dingemanse, Julija Baranova, Joe Blythe, Penelope Brown, Tyko Dirksmeyer, Paul Drew, et al. 2013. Huh? What? - A first survey in 21 languages. In Makoto Hayashi, Geoffrey Raymond \& Jack Sidnell (eds.), Conversational repair and human understanding, 343-380. Cambridge: Cambridge University Press.

Enfield, N. J., Tanya Stivers \& Stephen C. Levinson. 2010. Question-response sequences in conversation across ten languages: An introduction. Journal of Pragmatics 42(10). 2615-2619. DOI: $10.1016 /$ j.pragma.2010.04.001

Firth, J. R. 1930. The tongues of men, and speech. London: Oxford University Press.

Fox, Barbara A., Hayashi, Makoto \& Jasperson Robert. 1996. Resources and repair: a crosslinguistic study of syntax and repair. In Elinor Ochs, Emanual A. Schegloff \& Sandra A. Thompson (eds.), Interaction and Grammar, 185-237. Cambridge: Cambridge University Press. DOI: 10.1017/CBO9780511620874.004

Gabelentz, Georg von der. 1891. Die Sprachwissenschaft, ihre Aufgaben, Methoden und bisherigen Ergebnisse, 2nd edn. London: Routledge/Thoemmes Press.

Goffman, Erving. 1971. Relations in public. New York: Harper \& Row.

Gussenhoven, Carlos. 2004. The phonology of tone and intonation. Cambridge: Cambridge University Press. DOI: 10.1017/CBO9780511616983

Halliday, M. A. K. 1970. Language structure and language function. In John Lyons (ed.), New horizons in linguistics, 140-165. London: Penguin.

Halliday, M. A. K. 1971. Language in a social perspective. Educational Review 23(3). 165-188. DOI: $10.1080 / 0013191710230302$

Hayashi, Makoto, Geoffrey Raymond \& Jack Sidnell (eds.). 2013. Conversational repair and human understanding. Cambridge: Cambridge University Press.

Heritage, John. 2012. The epistemic engine: Sequence organization and territories of knowledge. Research on Language \& Social Interaction 45(1).30-52.DOI: 10.1080/08351813.2012.646685

Heritage, John \& Geoffrey Raymond. 2005. The terms of agreement: Indexing epistemic authority and subordination in talk-in-interaction. Social Psychology Quarterly 68(1). 15-38. DOI: 10.1177/019027250506800103

Hinde, R. A. 1976. Interactions, relationships and social structure. Man 11(1). 1-17. DOI: $10.2307 / 2800384$

Horn, Laurence. 1984. Toward a new taxonomy for pragmatic inference: Q-based and R-based implicature. In Deborah Schiffrin (ed.), Meaning, form, and use in context (GURT '84), 11-42. Washington: Georgetown University Press. http://www.princeton.edu/ harman/ Courses/PHI534-2012-13/Oct8/horn1984.pdf.

Jefferson, Gail. 1972. Side sequences. In David N. Sudnow (ed.), Studies in social interaction, 294-338. New York: MacMillan/The Free Press.

Kamio, Akio. 1994. The theory of territory of information: The case of Japanese. Journal of Pragmatics 21(1). 67-100. DOI: 10.1016/0378-2166(94)90047-7 
Kim, Kyu-hyun. 1999. Other-initiated repair sequences in Korean conversation: Types and functions. Discourse and Cognition 6. 141-168.

Lerner, Gene H. 2004. On the place of linguistic resources in the organization of talk-in-interaction: Grammar as action in prompting a speaker to elaborate. Research on Language \& Social Interaction 37(2). 151-184. DOI: 10.1207/s15327973rlsi3702_3

Levinson, Stephen C. 2000. Presumptive meanings: The theory of generalized conversational implicature. Cambridge: MIT Press.

Moerman, Michael. 1977. The preference for self-correction in a Tai conversational corpus. Language 53(4). 872-882. DOI: 10.2307/412915

Moerman, Michael \& Harvey Sacks. 1988. On "Understanding" in the analysis of natural conversation. In Michael Moerman (ed.), Talking culture: Ethnography and conversation analysis, 180-186. Philadelphia: University of Pennsylvania Press.

Ochs, Elinor. 1984. Clarification and culture. In Deborah Schiffrin (ed.),GURT'84: Meaning, form, and use in context: Linguistic applications. Washington, D. C.: Georgetown University Press.

Ohala, John J. 1984. An ethological perspective on common cross-language utilization of F0 of voice. Phonetica 41(1). 1-16. DOI: 10.1159/000261706

Olivier, Cl. 1985. L'art et la manière : 'comment' dans les stratégies discursives. Langages 20(80). 71-98. DOI: 10.3406/lgge.1985.1514

Purver, Matthew. 2004. The theory and use of clarification requests in dialogue. King's College, University of London, August. http://www.dcs.qmul.ac.uk/mpurver/papers/purver04thesis.pdf.

Robinson, Jeffrey D. 2006. Managing trouble responsibility and relationships during conversational repair. Communication Monographs 73. 137-161. DOI: 10.1080/03637750600581206

Robinson, Jeffrey D. 2013. Epistemics, action formation, and other-initiation of repair: The case of partial questioning repeats. In Makoto Hayashi, Geoffrey Raymond \& Jack Sidnell (eds.), Conversational repair and human understanding, 261-292. Cambridge: Cambridge University Press.

Robinson, Jeffrey D. \& Heidi Kevoe-Feldman. 2010. Using full repeats to initiate repair on others' questions. Research on Language \& Social Interaction 43(3). 232-259. DOI: $10.1080 / 08351813.2010 .497990$

Sacks, Harvey. 1992. Lectures on conversation. London: Blackwell.

Sacks, Harvey \& Emanuel A. Schegloff. 1979. Two preferences in the organization of reference to persons in conversation and their interaction. In George Psathas (ed.), Everyday language: Studies in ethnomethodology, 15-21. New York: Irvington Publishers.

Sapir, Edward. 1921. Language. New York: Harcourt, Brace.

Schegloff, Emanuel A. 1987. Between macro and micro: Contexts and other connections. In Jeffrey C. Alexander, Bernhard Giesen, Richard Munch \& Neil J. Smelser (eds.), The micromacro link, 207-234. Los Angeles: University of California Press.

Schegloff, Emanuel A. 1996. Confirming allusions: Toward an empirical account of action. The American Journal of Sociology 102(1). 161-216. DOI: 10.1086/230911

Schegloff, Emanuel A. 1997. Practices and actions: Boundary cases of other-initiated repair. Discourse Processes 23(3). 499-545. DOI: 10.1080/01638539709545001

Schegloff, Emanuel A. 2000. When 'others' initiate repair. Applied Linguistics 21(2). 205-243. DOI: 10.1093/applin/21.2.205

Schegloff, Emanuel A. 2004. On dispensability. Research on Language \& Social Interaction 37(2). 95-149. DOI: 10.1207/s15327973rlsi3702_2 
Schegloff, Emanuel A. 2005. On complainability. Social Problems 52(4). 449-476. DOI: 10.1525/ sp.2005.52.4.449

Schegloff, Emanuel A. 2006. Interaction: The infrastructure for social institutions, the natural ecological niche for language, and the arena in which culture is enacted. In N. J. Enfield \& Stephen C. Levinson (eds.), Roots of human sociality: Culture, cognition and interaction, 70-96. Oxford: Berg.

Schegloff, Emanuel A. 2007. Sequence organization in interaction: A primer in conversation analysis, vol. 1. Cambridge: Cambridge University Press. DOI: 10.1017/CBO9780511791208

Schegloff, Emanuel A., Gail Jefferson \& Harvey Sacks. 1977. The preference for self-correction in the organization of repair in conversation. Language 53(2). 361-382.

Selting, Margret. 1987a. Verständigungsprobleme. Eine empirische Analyse am Beispiel der Bürger-Verwaltungs-Kommunikation. Tübingen: Niemeyer. DOI: 10.1515/9783111357669

Selting, Margret. 1987b. Reparaturen und lokale Verstehensprobleme oder: zur Binnenstruktur von Reparatursequenzen. Linguistische Berichte 108. 128-149.

Selting, Margret. 1987c. Fremdkorrekturen als Manifestationsformen von Verständigungsproblemen. Zeitschrift für Sprachwissenschaft 6(1). 37-58. DOI: 10.1515/ zfsw.1987.6.1.37

Selting, Margret. 1996. Prosody as an activity-type distinctive cue in conversation: The case of so-called "astonished" questions in repair-initiation. In Elizabeth Couper-Kuhlen \& Margret Selting (eds.), Prosody in conversation: Interactional studies, 231-270. Cambridge: Cambridge University Press. DOI: 10.1017/CBO9780511597862.008

Sidnell, Jack. 2006. Repair. In Jef Verschueren \& Jan-Ola Östman (eds.), Handbook of pragmatics. Amsterdam: John Benjamins.

Sidnell, Jack. 2007. Repairing person reference in a small Caribbean community. In N. J. Enfield \& Tanya Stivers (eds.), Person reference in interaction: Linguistic, cultural and social perspectives, 281-308. Cambridge: Cambridge University Press.

Sidnell, Jack. 2010a. Conversation analysis: An introduction. Chichester: Wiley-Blackwell.

Sidnell, Jack. 2010b. Questioning repeats in the talk of four-year-old children. In H. Gardner \& M. Forrester (eds.), Analysing interactions in childhood: Insights from conversation analysis, 23-41. London: John Wiley.

Sorjonen, Marja-Leena. 1996. On repeats and responses in Finnish conversations. In Elinor Ochs, Emanuel A. Schegloff \& Sandra A. Thompson (eds.), Interaction and grammar, 277327. Cambridge: Cambridge University Press. DOI: 10.1017/CBO9780511620874.006

Stivers, Tanya. 2005. Modified repeats: One method for asserting primary rights from second position. Research on Language \& Social Interaction 38(2). 131-158. DOI: 10.1207/ s15327973rlsi3802_1

Stivers, Tanya, Lorenza Mondada \& Jakob Steensig (eds.). 2011. The morality of knowledge in conversation. Cambridge: Cambridge University Press. DOI: 10.1017/CBO9780511921674

Stivers, Tanya \& Jeffrey D. Robinson. 2006. A preference for progressivity in interaction. Language in Society 35(3). 367-392. DOI: 10.1017/S0047404506060179

Suzuki, Kana. 2010. Other-initiated repair in Japanese: Accomplishing mutual understanding in conversation. Kobe: Kobe University dissertation.

Svennevig, Jan. 2008. Trying the easiest solution first in other-initiation of repair. Journal of Pragmatics 40(2). 333-348. DOI: 10.1016/j.pragma.2007.11.007

Ultan, Russell. 1978. Some general characteristics of interrogative systems. In Joseph H. Greenberg (ed.), Universals of human language 4, 211-248. Stanford: Stanford University Press. 
Wu, Ruey-Jiuan Regina. 2008. Repetition in the initiation of repair. In Jack Sidnell (ed.), Conversation analysis: Comparative perspectives, 31-59. Cambridge: Cambridge University Press.

Corresponding author's address

Mark Dingemanse

MPI for Psycholinguistics

PB 310, 6500 AH, Nijmegen

mark.dingemanse@mpi.nl 